\title{
Intracranial Dural Arteriovenous Fistula: Microneurosurgery Basics and Tricks
}

\author{
Anna Piippo, Mardjono Tjahjadi, \\ and Juha Hernesniemi
}

\subsection{Introduction}

Intracranial dural arteriovenous fistulas (DAVFs) are acquired lesions characterized by a region of abnormal arteriovenous fistulous connection within the dura. DAVFs contribute to $10-15 \%$ of all AVM intracranially as reported by Newton et al. from 1969 [1]. In common population the probable rates were $0.15-0.29$ per 100,000 people per year [2,3]. Median age of DAVF patients is between 50 and 60 years, but it may present at any age $[4,5]$.

\subsection{Classification}

There are several classifications for DAVF, but the most commonly used ones are the simplified Borden classification and the Cognard classification, which is a modification of Djindjian classification [6-8].

\subsubsection{Simplified Borden Classification}

\begin{tabular}{|l|l|}
$\begin{array}{l}\text { Lesion } \\
\text { type }\end{array}$ & Definition \\
\hline I & $\begin{array}{l}\text { Drains directly anterograde to major sinus of } \\
\text { the vein }\end{array}$ \\
\hline II & $\begin{array}{l}\text { Drains to sinus of the vein with retrograde } \\
\text { drainage back to subarachnoid veins }\end{array}$ \\
\hline III & $\begin{array}{l}\text { Drains directly to subarachnoid veins (CVD } \\
\text { only) }\end{array}$ \\
\hline
\end{tabular}

\subsubsection{Cognard Classification}

\begin{tabular}{|c|c|}
\hline $\begin{array}{l}\text { Lesion } \\
\text { type }\end{array}$ & Definition \\
\hline I & $\begin{array}{l}\text { Drains to dural venous sinus (DVS) with } \\
\text { anterograde flow }\end{array}$ \\
\hline IIa & Drains to DVS with retrograde flow \\
\hline $\mathrm{IIb}$ & $\begin{array}{l}\text { Drains to DVS with anterograde flow }+ \\
\text { CVD }\end{array}$ \\
\hline $\mathrm{IIa}+\mathrm{b}$ & Drains to DVS with retrograde flow + CVD \\
\hline III & $\begin{array}{l}\text { Drains directly to subarachnoid veins (CVD } \\
\text { only) }\end{array}$ \\
\hline IV & $\begin{array}{l}\text { Drains directly to subarachnoid veins with } \\
\text { ectasia of the draining vein }\end{array}$ \\
\hline V & $\begin{array}{l}\text { Drains directly into spinal perimedullary } \\
\text { veins }\end{array}$ \\
\hline
\end{tabular}

\footnotetext{
A. Piippo · M. Tjahjadi · J. Hernesniemi $(\bowtie)$

Department of Neurosurgery, Helsinki University Central Hospital, Helsinki, Finland

e-mail: anna.piippo@hus.fi; juha.hernesniemi@hus.fi
} 


\subsection{Signs and Symptoms}

Clinically, DAVF presentation is determined by their location and pattern of venous outflow. Below are common clinical signs and symptoms in relationship with their location.

\begin{tabular}{ll}
$\begin{array}{l}\text { DAVFs at transverse- } \\
\text { sigmoid sinus }\end{array}$ & Pulsatile tinnitus \\
\hline $\begin{array}{l}\text { DAVFs at cavernous } \\
\text { sinus }\end{array}$ & $\begin{array}{l}\text { Exophthalmos, chemosis, } \\
\text { and blindness (Fig. 25.1) }\end{array}$ \\
\hline $\begin{array}{l}\text { Superior sagittal sinus } \\
\text { DAVFs }\end{array}$ & $\begin{array}{l}\text { Hemorrhage, local venous } \\
\text { congestion, brain edema, } \\
\text { and ischemia }\end{array}$ \\
$\begin{array}{l}\text { DAVFs with } \\
\text { perimedullary draining } \\
\text { vein }\end{array}$ & $\begin{array}{l}\text { pyolopathy and } \\
\text { progressive tetraplegia }\end{array}$ \\
\hline
\end{tabular}

\subsection{Investigation}

\subsubsection{DSA}

Digital subtraction angiography (DSA) is still the best way to show DAVF. DSA accurately illustrates the flow dynamic of the fistula and the cerebral circulation of the brain. This information is critical both for the surgical planning and for the evaluation of the treatment (Fig. 25.2).

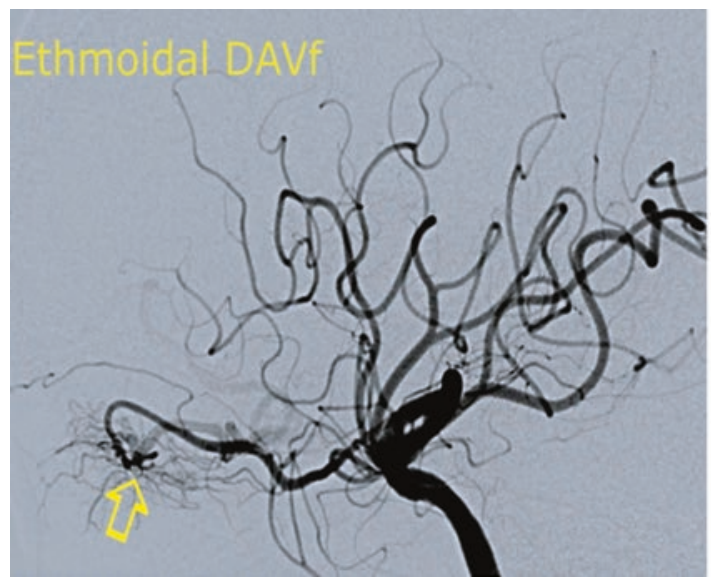

Fig. 25.2 Left: The DSA of the ethmoidal DAVF showing the fistula connection Borden type III fed by ophthalmic artery and drained through the cortical veins. Right:

\subsubsection{MRA (Magnetic Resonance Angiography) (Fig. 25.3)}

In case of Borden type 1 DAVFs without CVD, MRI is usually normal. It may show vein dilatation, venous occlusion, or, after contrast enhancement, increased vascularity around the involved sinus. Venous congestion may be seen on MRI T2 as a signal changes to hyperintensity that diffusely involves the cortex in DAVFs with CVD, either at the cerebrum or cerebellum. Time-of-flight MRI (TOF MRI) now is widely available and usually the primary screening tool when the DAVF is suspected [9-11]. With time-resolved imaging of contrast kinetics (TRICKS) technique introduced

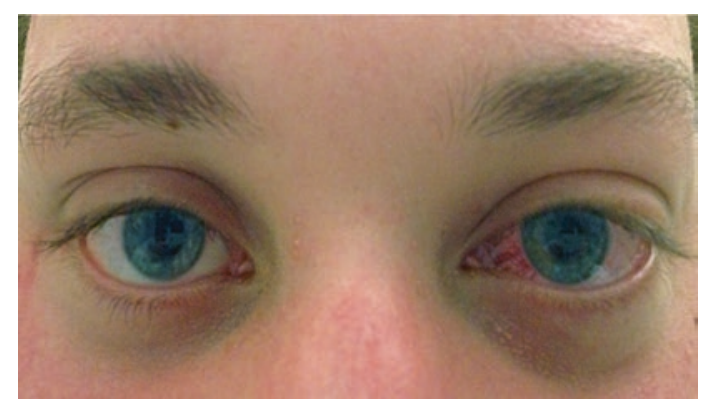

Fig. 25.1 Slight chemosis and exophthalmos of the left eye in a patient with left cavernous sinus DAVF

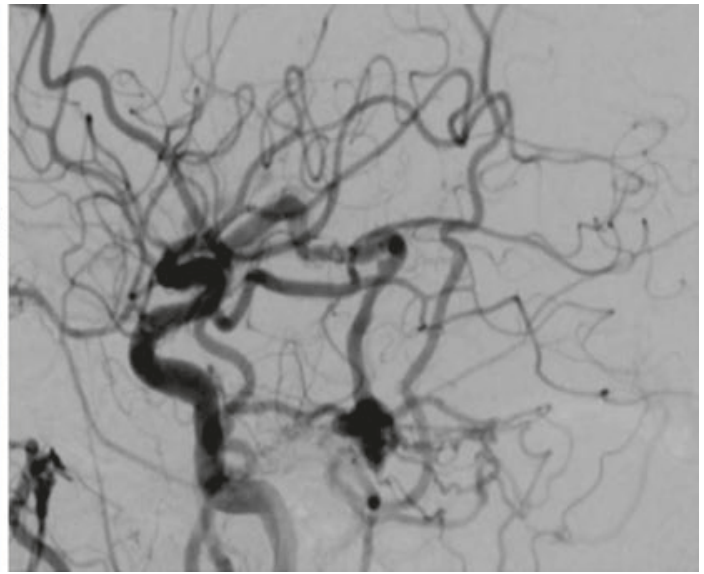

Tentorial DAVF Borden type III fed by meningohypophyseal branch and drained through the cortical veins 

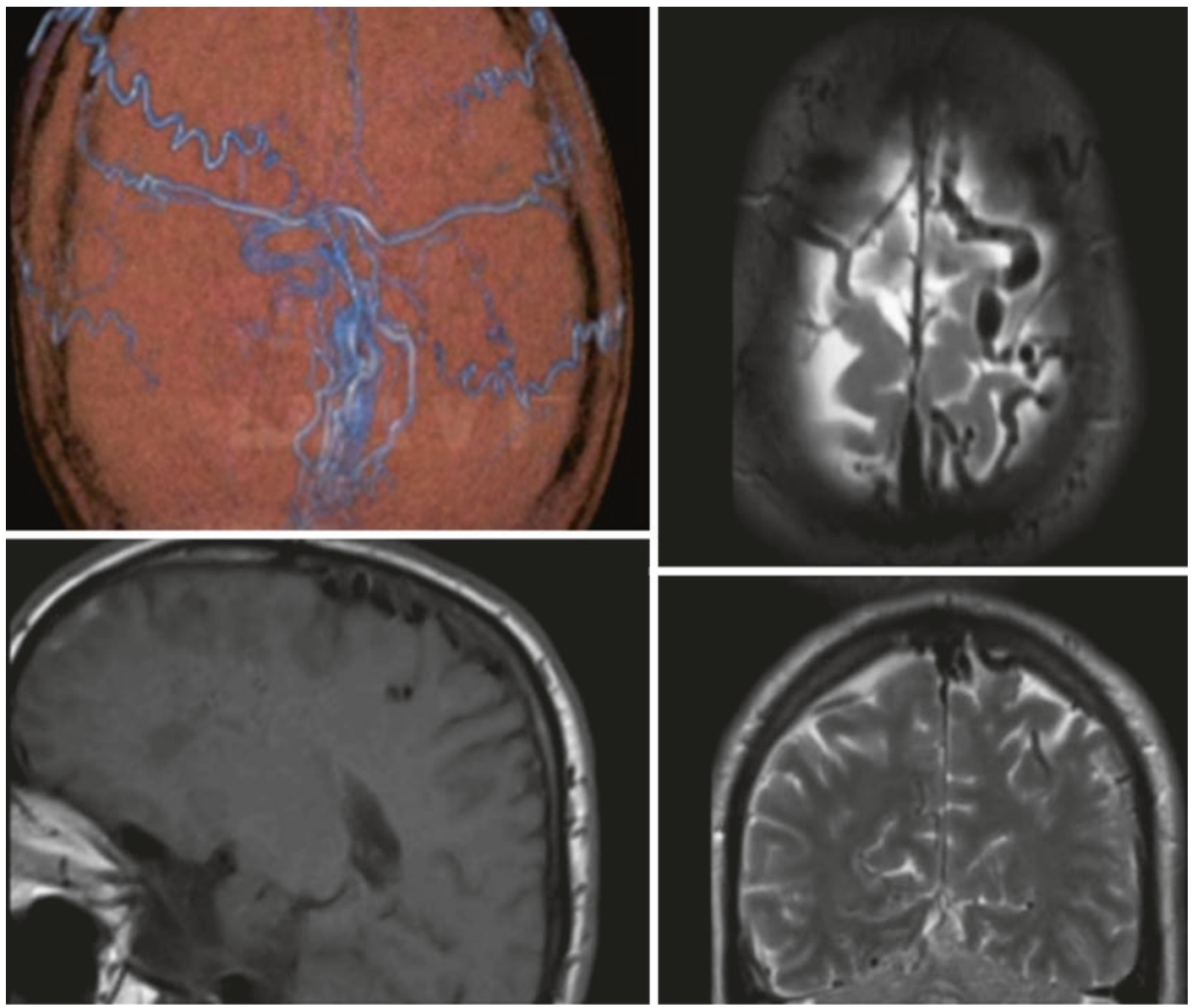

Fig. 25.3 MRA shows a superior sagittal sinus DAVF Borden type II fed by the meningeal arteries and drained through the superior sagittal sinus with retrograde flow to the cortical veins

in 1996 [12], arterial and venous phases of contrast passage through the brain can be separated, showing the flow dynamics of the DAVFs. TRICKS has a better sensitivity over TOF MRA to detect DAVFs and a useful noninvasive imaging method during the treatment and follow-up $[13,14]$. TRICKS has less accurate spatial resolution than DSA, and therefore DSA is still needed for studying the detailed anatomy of DAVFs.

\subsubsection{CTA (Computed Tomography Angiography)}

Computed tomography is the primary method for ruptured DAVFs showing intracerebral hemor- rhage (ICH), sometimes subdural hemorrhages (SDH), subarachnoid hemorrhages, or intraventricular hemorrhages (IVH). CT and CTA can show abnormal vessels, venous ectasia, and pouches related to the DAVFs, but the drawback is its lack of temporal solution [15]. Dynamic CTA can show pathologic flow dynamics in intracranial vessels indicating the presence of DAVFs [16].

\subsection{Preoperative Preparation}

Careful analysis of the angiographic images and angioarchitecture of DAVF when planning the surgery is crucial for achieving complete eradication of the fistula, preserving normal vasculature 
and avoiding pitfalls of the surgery. Preoperative embolization of the DAVF can reduce the bleeding during operation. Bleeding can also be reduced by sustaining moderate hypotension (systolic blood pressure around $100 \mathrm{mmHg}$ ) during the operation.

\subsection{Approach and Step of Surgery}

\subsubsection{Transverse and Sigmoid Sinus DAVFs}

It could be approached through lateral suboccipital approach. Patient is set up with park-bench position and the head is higher than the heart level. The head is tilted laterally to the opposite side, and the shoulder is retracted caudally with tape to achieve a correct trajectory of the approach.

\subsubsection{Steps of Surgery}

- A curved incision or the shape of question mark incision is placed about $1 \mathrm{in}$. behind the mastoid process (Fig. 25.4).

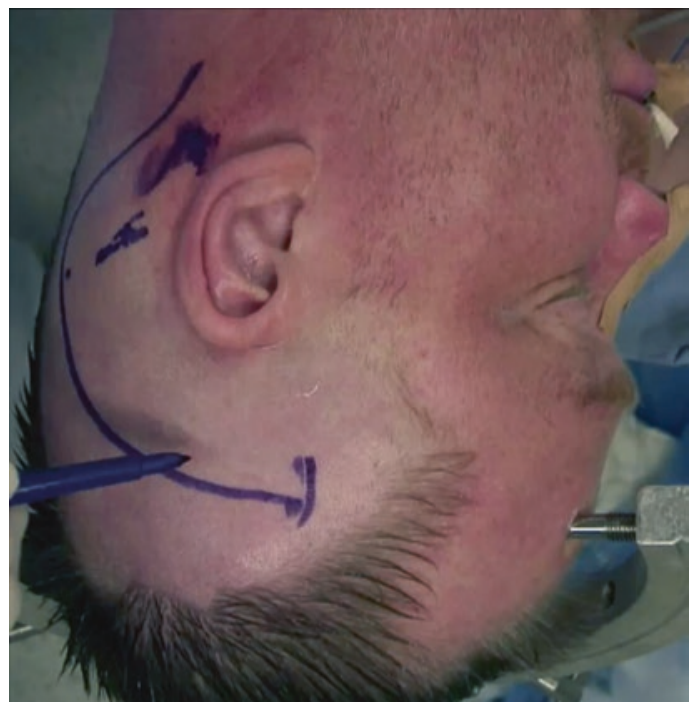

Fig. 25.4 Large question mark skin marking for lateral suboccipital approach to treat the transverse-sigmoid sinus DAVF
- Any bleeding from the skin should be cautiously coagulated to prevent a later excessive bleeding.

- Several burr holes (three to four) are placed, and a large suboccipital bone flap is removed by cutting the medial part with craniotome, and the lateral margin by drilling off the bone.

- Lateral margin of the opening is further drilled away as far as laterally as possible to achieve a good visibility and control around the sigmoid sinus.

- If we get into the mastoid air cells, they have to be meticulously sealed with fat or muscle graft, and then add the fibrin glue to avoid CSF leak.

\subsubsection{Occlusion of the Fistula}

- If the venous sinus is open and it serves as a main venous drainage, the feeding arteries are coagulated and cut.

- In case the sinus is occluded or nonfunctional, or we find a retrograde flow into the veins at the cortex, then it may be removed.

- The medial part of the sinus is ligated first. Then using the lateral part of the sinus is resected, and the remaining part of the proximal sinus is filled using oxidized cellulose $\left(\right.$ Surgicel ${ }^{\circledR}$ ) or another option is using muscle then ligated.

- The vein of Labbé should be preserved to prevent venous infarction.

\subsubsection{Middle Fossa and Cavernous Sinus DAVFs}

It could be approached through lateral supraorbital (LSO) approach. Position of the patient is supine, and the head is higher than the heart level, rotated $30^{\circ}$ to contralateral side and tilted slightly (Fig. 25.5).

\subsubsection{Steps of Surgery}

- One-layer frontotemporal skin and muscle flap is made extending about an inch above the zygomatic arch (Fig. 25.6). 

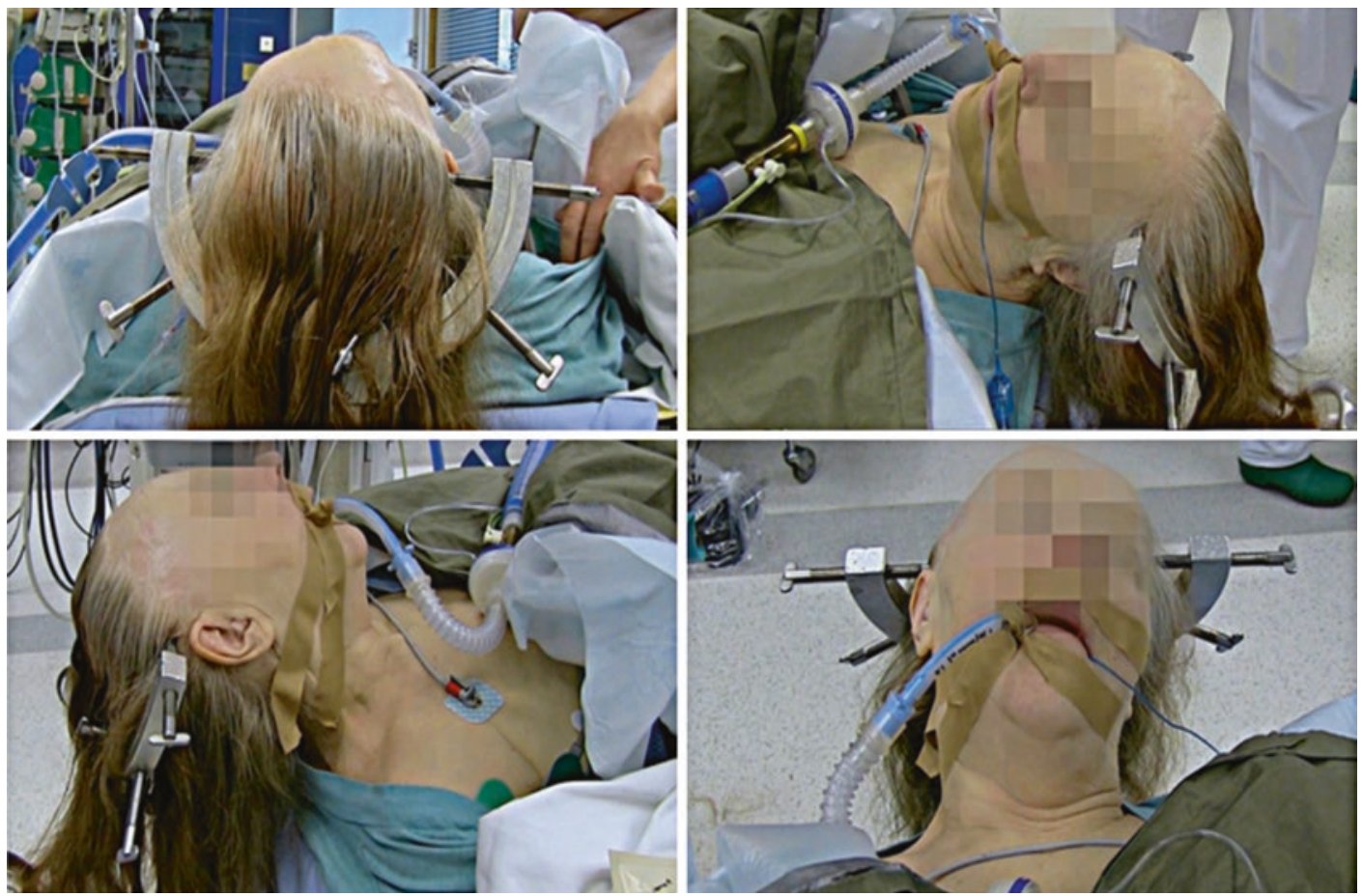

Fig. 25.5 Positioning of the right LSO approach. The LSO approach is usually used to operate on cavernous sinus DAVF and sometimes for the ethmoidal/frontobasal DAVF

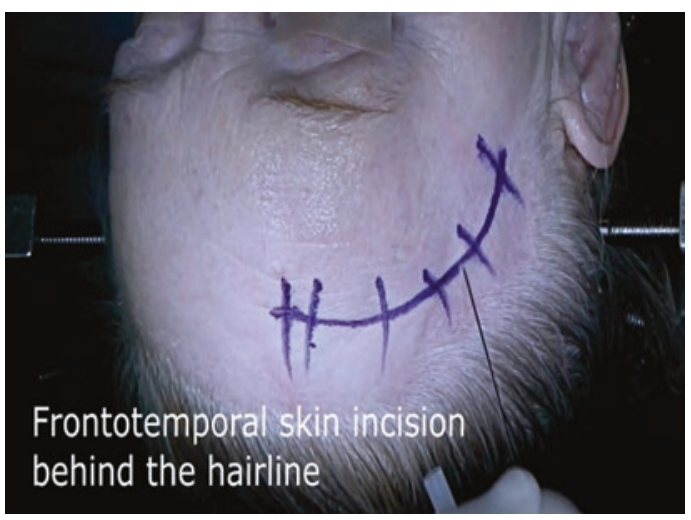

Fig. 25.6 Frontotemporal skin incision for LSO approach is done behind the hairline

- One burr hole is made on the superior insertion of the temporalis muscle and a small bone flap $3 \times 5 \mathrm{~cm}$ is elevated.
- Sphenoid ridge at its lateral part should be drilled with a diamond high-speed drill.

- The medial part of sphenoid ridge including anterior clinoid process is removed with Sonopet drill.

\subsubsection{Occlusion of the Fistula}

$$
\text { (Fig. 25.7) }
$$

- After exposing the wall of the cavernous sinus, it is opened with a very small incision.

- From this opening, fibrin glue is injected with blunt needle, and a pack of Surgicel ${ }^{\circledR}$ is applied on top of it.

- Then do another one repetitively at multiple places of cavernous sinus wall, and keep doing the same thing until we occlude all the fistulas.

- While doing the injections, it is important to make sure and keep the carotid artery flow adequately. 

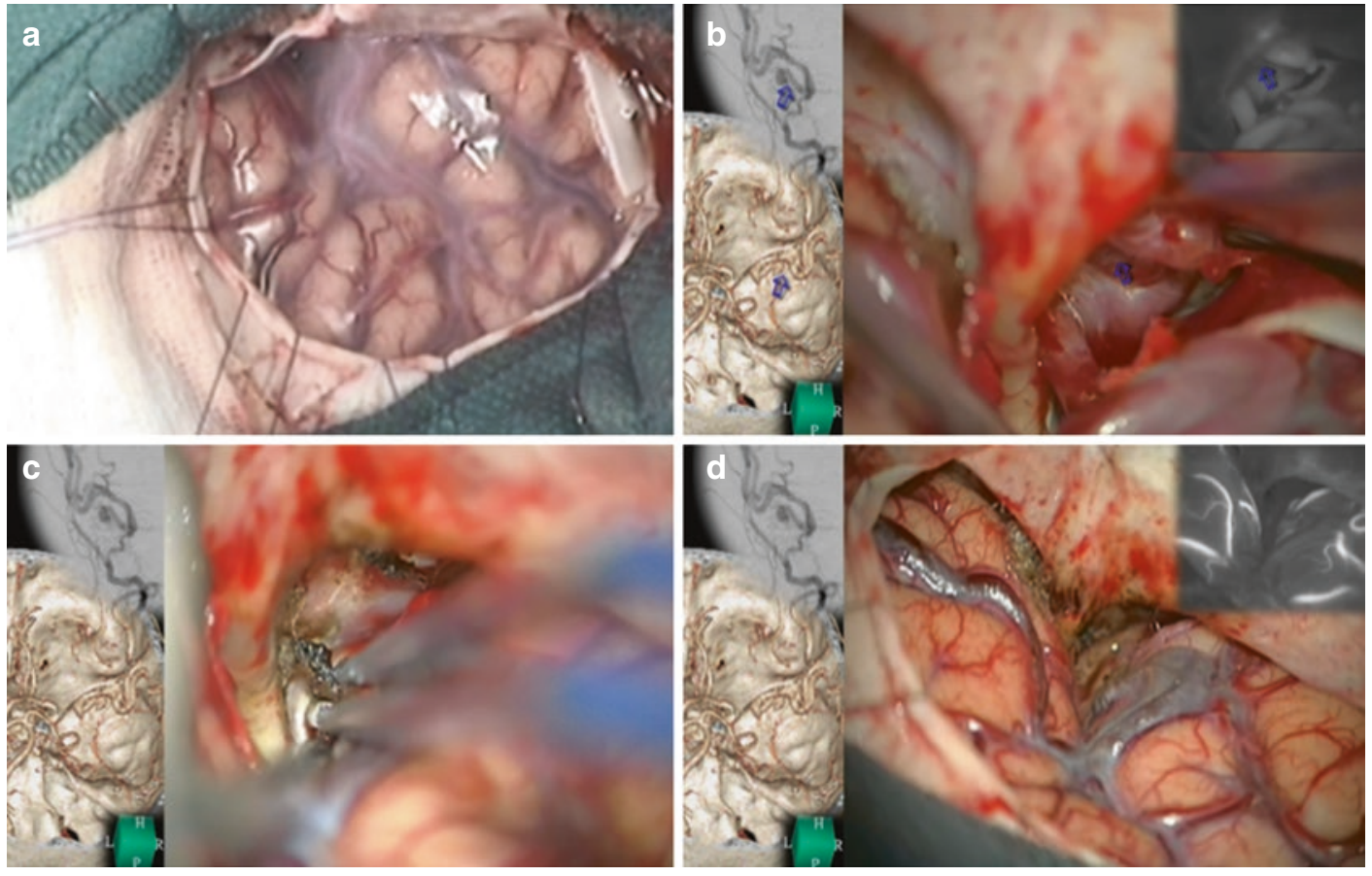

Fig. 25.7 Steps of surgery. (a) Exposure after the dura opening. (b) Confirmation of the draining veins. (c) Coagulation of the draining veins and disconnection of the fistula. (d) ICG-VA confirmed the disconnection of DAVF

- If the fistula does not involve the cavernous sinus, then identification of the draining veins should be done with the guidance of ICG-VA.

- Coagulation and disconnection of the draining veins should be performed cautiously to avoid the injury of the normal draining veins.

- To verify the occlusion of the fistula and the patency of the carotid artery, intraoperative indocyanine green video angiography (ICG-VA) or conventional angiography is performed.

\subsubsection{Tentorial DAVFs}

It could be approached through subtemporal approach. Position of the patient is following park-bench position.

\subsubsection{Steps of Surgery}

- A small horseshoe-like incision from above the zygomatic arch curving posteriorly just above the ear lobe is placed (Fig. 25.8).

- Two burr holes are placed, one close to the origin of zygomatic arch, where the dura is often

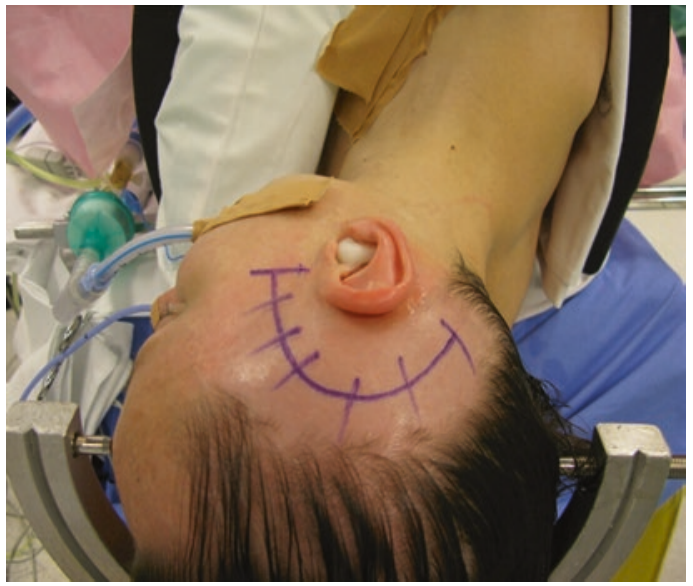

Fig. 25.8 The position and skin incision marking for subtemporal approach

tightly attached to the bone, and another at the cranial border, to elevate a small bone flap.

- The temporobasal bone is drilled until the origin of the floor of the middle fossa to widen the bone opening.

- Cut the dura at its base caudally to expose subtemporal space. 
- Tentorial edge is then quickly reached and cisterns opened to relax the brain with minimal retraction of the temporal lobe.

- The temporal lobe is elevated gradually starting anteriorly from the temporal pole and moving posteriorly.

- The retraction should be increased gradually. Finally, a rather wide retractor is placed to retain space.

\subsubsection{Occlusion of the Fistula}

- To get a better visualization to the fistulous site, the tentorial edge is cut at posterior to the insertion of trochlear nerve and then lifted upward using small Aesculap ${ }^{\circledR}$ clip.

- The feeding arteries along the dura are coagulated and cut.

- The occlusion of the fistula can be verified by using intraoperative ICG-VA or DSA.

\subsubsection{Frontobasal DAVFs}

It could be approached through anterior interhemispheric approach. The patient is seated in a semi-sitting position.

\subsubsection{Steps of Surgery}

- A linear incision is placed behind the hairline.

- Make two burr holes at midline over SSS.

- Bone flap is cut with a craniotome extending both sides of the sinus.

\subsubsection{Occlusion of the Fistula}

- Frontobasal DAVFs often have feeding arteries from both sides.

- The falx is coagulated and divided close to crista galli to reach the feeders from the contralateral side.

- Feeding arteries within dura and draining cortical veins are coagulated and cut from both sides of the falx.

\subsubsection{Superior Sagittal Sinus DAVFs}

It could be approached through midline approach. Position of the patient is semi-sitting or we also may do it with supine position.

\subsubsection{Steps of Surgery}

- A linear incision is placed behind the hairline.

- Making two burr holes at midline over SSS.

- Bone flap is cut with a craniotome extending both sides of the sinus.

- If the frontal sinus opens during approach for frontobasal DAVFs, the endonasal mucosa is stripped of and the sinus is packed with fat and covered with pericranium and fibrin glue.

\subsubsection{Occlusion of the Fistula}

(Fig. 25.9)

- Superior sagittal sinus DAVFs also often have feeding arteries from both sides.

- Feeding arteries within dura and draining cortical veins are coagulated and cut from both sides of the SSS.

- Tack-up sutures are used to lift the dura and prevent excessive bleeding and formation of epidural hematoma.

- Preserving SSS is extremely important in the lesions of the posterior part of the SSS because it serves as the major route for venous outflow of the cerebral hemispheres.

- If the DAVF is located in anterior third of SSS, this part of sinus can be resected.

- Dura is left open to prevent recurrence of the fistulous connections.

\subsection{Expert Opinion/Suggestion to Avoid Complication}

- Microsurgery is the first-line treatment in tentorial or frontobasal DAVFs. Others should primarily be treated by endovascular and/or radiosurgical means. Microsurgery is also recommended if the endovascular and/or radiological effort could not achieve total occlusion, and the patient presents with intolerable symptoms or CVD is still present.

- The most dangerous complications of DAVF treatment, whether it was microsurgical or endovascular, are severe brain swelling and hemorrhagic infarction due to sudden occlusion of the DAVF.

- The best way to avoid these complications is to carefully study the angioarchitecture and flow dynamics of the DAVF before treatment. 

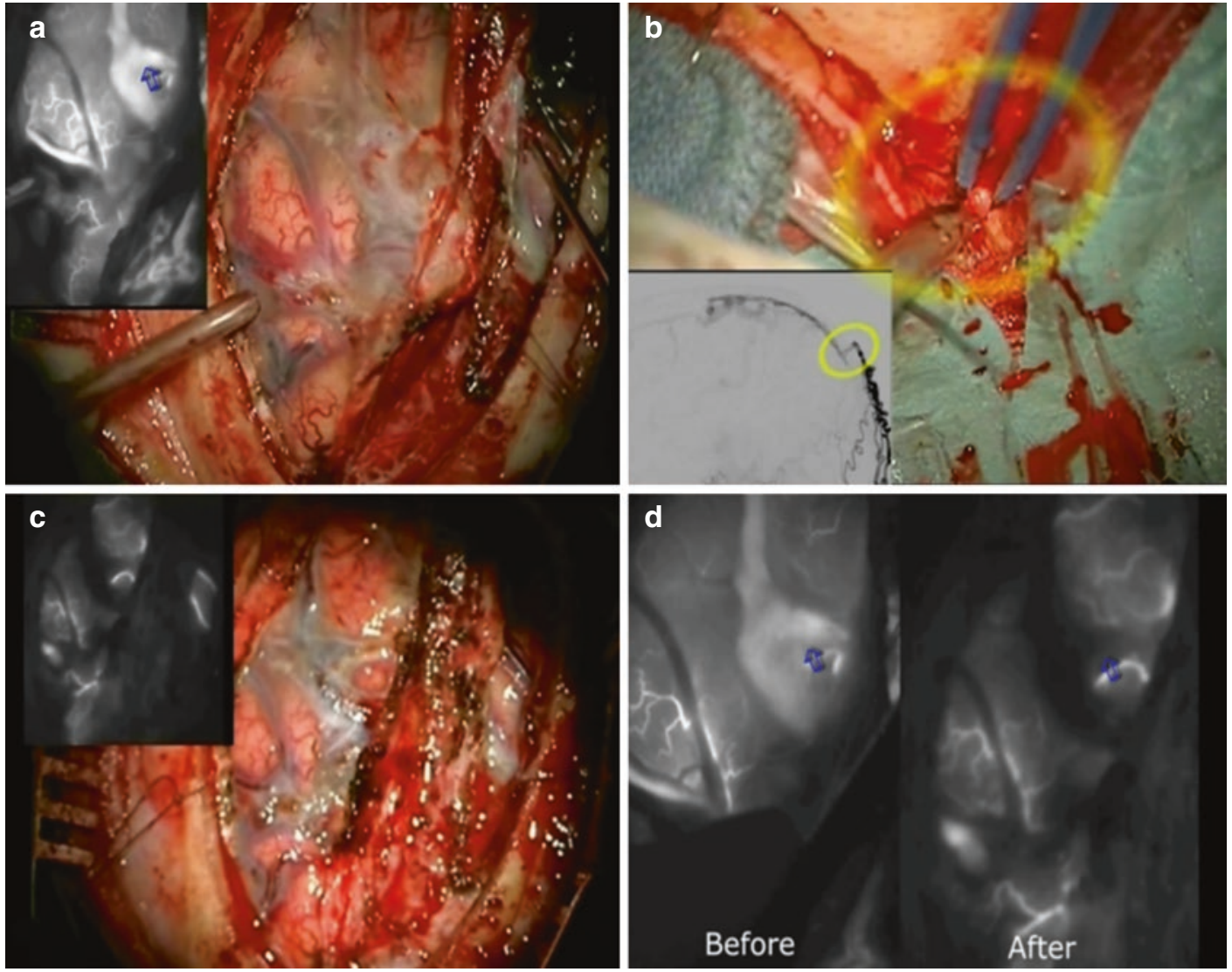

Fig. 25.9 Steps of surgery. (a) Exposure after the dura opening reveals an early venous filling. (b) Coagulation of the feeder arteries from dura mater which was shown from the preoperative DSA. (c) Condition after the feeding

arteries coagulation. IVG-VA showed no early venous filling anymore. (d) Comparison of ICG-VA before and after feeding artery coagulation

- Identification and preservation of the vein of Labbé during the microsurgery of transverse and sigmoid sinus DAVF are crucial.

- Heavy arterial bleeding from the enlarged extracranial feeding arteries with high flow through the bone into the fistula can make the microsurgery a great challenge already from the skin incision.

- To prevent the highly vascularized DAVFs from bleeding extensively, hemostasis should be done carefully in every phase of the surgery using a high-power bipolar coagulation.

- To achieve a good control of all the fistulous connections, large craniotomies with three to four burr holes are used to expose the lesion.

- The bleeding from the bone margins is managed by the heat produced by drilling the bone with a large diamond drill without irrigation ("hot drilling").

- Using operative microscope from the early stages of the surgery is crucial to visualize and control the bleeding.

- In of case heavy bleeding during surgery from the affected sinus, then we may use Surgicel ${ }^{\circledR}$, fibrin glue, and muscle are packed over the sinus.

- A slight hypotension (systolic pressure $100 \mathrm{mmHg}$ ) is recommended during the surgery and 1-2 days after it to prevent postoperative hematomas. 


\subsection{Verification of Complete Occlusion}

\subsubsection{Intraoperative Imaging}

- Indocyanine green (ICG) angiography is a helpful tool for intraoperative imaging in DAVF cases.

- The fistulous site can be detected during the opening, and the occlusion of the fistula can be verified intraoperatively.

\subsubsection{Postoperative Imaging}

- The primary method for verification of DAVF occlusion postoperatively is DSA, because all the small feeding arteries may not show in ICG-VA or CTA.

- Later during follow-up, MRA and/or TRICKS is used to verify the occlusion of the fistula.

\subsection{Complications of Microsurgery}

In our series, the complications were: [4]

- Severe bleeding more than $1000 \mathrm{ml}$ occurred in $10(8.6 \%)$.

- Ischemic complication. Seventeen (15\%) patients had postoperative infarction.

- Hemorrhagic complications. Three (2.6\%) patients developed intracerebral hemorrhages (ICH) that were observed, and two (1.7\%) patients developed epidural hematomas necessitating evacuation.

- Other complications include postoperative septicemia, urinary tract infection, pneumonia, postoperative meningitis despite routine prophylactic antibiotics, wound infection, pulmonary embolism, cardiac infarction, gastrointestinal bleeding, and deep venous thrombosis.

\subsubsection{Neuro-fuctioning ourcome}

The length of follow-up is up to 15.9 years, with a median of 3.2 years. There are 103 patient's data available for this follow-up. The Glasgow Outcome Scale at 3 months shows 98 (84\%) patients had GOS 4-5, $2(1.7 \%)$ were severely disabled, and 3 (2.6\%) died.

\section{References}

1. Newton TH, Cronqvist S. Involvement of dural arteries in intracranial arteriovenous malformations. Radiology. 1969;93(5):1071-8.

2. Al-Shahi R, et al. Prospective, population-based detection of intracranial vascular malformations in adults: the Scottish Intracranial Vascular Malformation Study (SIVMS). Stroke. 2003;34(5):1163-9.

3. Satomi J, Satoh K. Epidemiology and etiology of dural arteriovenous fistula. Brain Nerve. 2008;60(8):883-6.

4. Piippo A, et al. Characteristics and long-term outcome of 251 patients with dural arteriovenous fistulas in a defined population. J Neurosurg. 2013;118(5):923-34.

5. Piippo A, et al. Early and long-term excess mortality in 227 patients with intracranial dural arteriovenous fistulas. J Neurosurg. 2013;119(1):164-71.

6. Borden JA, Wu JK, Shucart WA. A proposed classification for spinal and cranial dural arteriovenous fistulous malformations and implications for treatment. J Neurosurg. 1995;82(2):166-79.

7. Cognard C, et al. Cerebral dural arteriovenous fistulas: clinical and angiographic correlation with a revised classification of venous drainage. Radiology. 1995;194(3):671-80.

8. Davies MA, et al. The validity of classification for the clinical presentation of intracranial dural arteriovenous fistulas. J Neurosurg. 1996;85(5):830-7.

9. Chen JC, Tsuruda JS, Halbach VV. Suspected dural arteriovenous fistula: results with screening MR angiography in seven patients. Radiology. 1992;183(1):265-71.

10. Kitajima M, et al. Retrograde cortical and deep venous drainage in patients with intracranial dural arteriovenous fistulas: comparison of MR imaging and angiographic findings. AJNR Am J Neuroradiol. 2005;26(6):1532-8.

11. van Vaals JJ, et al. "Keyhole" method for accelerating imaging of contrast agent uptake. J Magn Reson Imaging. 1993;3(4):671-5.

12. Korosec FR, et al. Time-resolved contrastenhanced 3D MR angiography. Magn Reson Med. 1996;36(3):345-51. 
13. Pekkola J, Kangasniemi M. Posterior fossa dural arteriovenous fistulas: diagnosis and follow-up with time-resolved imaging of contrast kinetics (TRICKS) at 1.5T. Acta Radiol. 2011;52(4):442-7.

14. Pollock BE, et al. Magnetic resonance imaging: an accurate method to evaluate arteriovenous malformations after stereotactic radiosurgery. J Neurosurg. 1996;85(6):1044-9.
15. Narvid J, et al. CT angiography as a screening tool for dural arteriovenous fistula in patients with pulsatile tinnitus: feasibility and test characteristics. AJNR Am J Neuroradiol. 2011;32(3):446-53.

16. Pekkola J, Kangasniemi M. Imaging of blood flow in cerebral arteries with dynamic helical computed tomography angiography (DHCTA) using a 64-row CT scanner. Acta Radiol. 2009;50(7):798-805.

Open Access This chapter is licensed under the terms of the Creative Commons Attribution 4.0 International License (http://creativecommons.org/licenses/by/4.0/), which permits use, sharing, adaptation, distribution and reproduction in any medium or format, as long as you give appropriate credit to the original author(s) and the source, provide a link to the Creative Commons license and indicate if changes were made.

The images or other third party material in this chapter are included in the chapter's Creative Commons license, unless indicated otherwise in a credit line to the material. If material is not included in the chapter's Creative Commons license and your intended use is not permitted by statutory regulation or exceeds the permitted use, you will need to obtain permission directly from the copyright holder. 